\title{
Perfil etiológico y susceptibilidad antimicrobiana del primer episodio de infección urinaria febril
}

\author{
José Gallegos, Sonia Márquez, Karina Morales y Anamaría Peña
}

\begin{abstract}
Facultad de Medicina Universidad Andrés Bello, Santiago, Chile. Estudiante de Medicina (JG) Pontificia Universidad Católica de Chile, Santiago. Facultad de Medicina (SM, AP) Complejo Asistencial Dr. Sótero del Río, Santiago, Chile. Laboratorio de Microbiología (KM).

Lugar donde se efectuó el estudio: Complejo Asistencial Dr. Sótero del Río.

Los autores declaran no tener conflictos de interés. No hubo financiamiento externo.

Este trabajo formó parte de la tesis para optar al título de Magíster en Ciencias Médicas con mención en Infecciones Intrahospitalarias y Epidemiología Hospitalaria de la Universidad de Valparaíso de Anamaría Peña Donati.

Recibido: 8 de abril de 2013 Aceptado: 19 de julio de 2013

Correspondencia a: Anamaría Peña Donati anapena@med.puc.cl
\end{abstract}

\section{Introducción}

L a infección del tracto urinario (ITU) corresponde a la invasión, multiplicación y colonización del tracto urinario por bacterias que proceden principalmente de la región perineal ${ }^{1,2}$. Existe en la actualidad consenso, en que toda ITU debe confirmarse por un cultivo de orina, que demuestre un recuento de colonias de una unidad formadora de colonia por $\mathrm{ml}(\mathrm{ufc} / \mathrm{ml})$ si la muestra es obtenida por punción vesical, $10^{4} \mathrm{ufc} / \mathrm{ml}$ si es por cateterismo vesical o mayor a $10^{5} \mathrm{ufc} / \mathrm{ml}$ si se usa recolector de orina o se toma por segunda micción ${ }^{1-3}$.

La incidencia de ITU en el niño no se conoce $^{1,3}$, pero corresponde a la segunda causa más frecuente de infección bacteriana en niños. Su frecuencia alcanza alrededor de $8 \%$ en las niñas y $2 \%$ en los varones bajo 7 años de edad $^{4}$; en recién nacidos llega a $1 \%$, con una proporción tres veces mayor en varones; en lactantes corresponde a $3-5 \%$ sin diferencia entre ambos sexos y en preescolares y escolares alcanza a $2 \%$ con una preponderancia mayor en mujeres ${ }^{2}$.

Las manifestaciones clínicas de la ITU son variadas, con un amplio espectro (desde bacteriuria asintomática a urosepsis) y su presentación clínica es diferente de acuerdo a la edad, aumentado la especificidad a medida que el niño crece y puede comunicar sus síntomas. En neonatos y lactantes bajo un año de edad suele ser poco específica y puede acompañarse o no de fiebre, por lo que siempre debe ser considerada en el diagnóstico diferencial de síndrome febril sin foco ${ }^{1,2,5,6}$.

Los principales microorganismos causantes de ITU son bacterias de origen intestinal, siendo Escherichia coli la más frecuente (sobre $86 \%$ ). El restante $14 \%$ se distribuye entre Klebsiella spp, Proteus vulgaris y P. mirabilis, Enterobacter spp, Enterococcus spp y Pseudomonas spp. Estas bacterias (no E. coli) se presentan con mayor frecuencia en pacientes inmunocomprometidos, infecciones nosocomiales asociadas a catéter vesical permanente, presencia de malformaciones de la vía urinaria, vejiga neurogénica e instrumentación urológica. En recién nacidos es posible encontrar Streptococcus agalactiae y en adolescentes Staphylococcus saprophyticus ${ }^{1,2,6-8}$.

El objetivo de este estudio fue describir los agentes etiológicos y su susceptibilidad antimicrobiana en el primer episodio de ITU febril en niños entre 2 meses y 5 años de edad.

\section{Pacientes y Métodos}

Estudio realizado en la Sub-dirección Médica del Niño (SDMN) del Complejo Asistencial Dr. Sótero del Río 
(CADSR), Santiago, que atiende una población infantil mayoritariamente beneficiaria (cotizantes o indigentes) de las comunas de La Florida, Puente Alto, San José de Maipo, Pirque, La Granja, San Ramón y La Pintana, cuyas familias tienen un nivel de pobreza e indigencia que alcanza a 12,3 y $3,4 \%$, respectivamente, mientras que el alfabetismo llega a $97,5 \%$ y la ruralidad es de $30 \%$, de acuerdo a datos del Censo año 2002.

Este es un estudio observacional de cohorte prospectiva que enroló, previa firma de consentimiento informado aprobado por el Comité de Ética institucional, a los pacientes que consultaron en la Unidad de Emergencia Infantil (UEI) del CADSR con fiebre $\left(\mathrm{T}^{\circ} \geq 38^{\circ} \mathrm{C}\right.$ axilar, en una toma) y sospecha de ITU, en el período noviembre de 2009-noviembre de 2010 y que cumplieron los siguientes criterios de inclusión: niños entre 2 meses y 5 años y urocultivo tomado por cateterismo trans-uretral, habiéndose realizado un aseo genital prolijo previamente, de acuerdo a la norma interna y efectuado antes del inicio de tratamiento antimicrobiano. Fueron excluidos los pacientes con fracaso de tratamiento antimicrobiano oral o intramuscular ambulatorio previo, antecedente conocido de: ITU, malformación de la vía urinaria, inmunodeficiencia, patología crónica conocida, y aquellos en que la muestra para urocultivo fuera obtenida por segundo chorro o recolector. Fueron eliminados aquellos con urocultivo de ingreso contaminado o negativo.

Todos los pacientes formaron parte de una cohorte con tratamiento antimicrobiano intravenoso ambulatorio (TAIA), se les instaló una vía venosa periférica (teflón) para administrar la primera dosis del antimicrobiano y fueron derivados a la Unidad de Hospitalización Transitoria (UHT) para su control diario hasta cambio a tratamiento vía oral. Se planificó un control clínico 3-5 días después de terminado el tratamiento para realizar urocultivo.

Se efectuó un registro prospectivo de los datos demográficos (género y edad), resultado de exámenes de laboratorio (sedimento de orina, urocultivo y antibiograma), antimicrobiano utilizado (intravenoso y oral), duración del tratamiento, evolución y complicaciones.

La muestra de orina fue sembrada en agar sangre y agar McConkey. Se consideró ITU si hubo crecimiento de un microorganismo con recuento mayor a $10^{4} \mathrm{ufc} / \mathrm{ml}$ en un urocultivo obtenido por cateterismo trans-uretral; negativo cuando no hubo crecimiento bacteriano; y contaminado cuando hubo crecimiento de un microorganismo que normalmente coloniza la piel o genitales, con recuento menor o igual a $10^{4} \mathrm{ufc} / \mathrm{ml}$, o si hubo crecimiento de dos o más o microorganismos en el urocultivo obtenido por cateterismo vesical.

El examen microscópico de orina se realizó tras centrifugar la muestra, entregando resultado por campo observado. Se consideró como indicador de ITU la presencia de más de 5 leucocitos por campo en la orina 9 .
La suceptibilidad bacteriana se analizó con la técnica de difusión en agar (según Kirby-Bauer). Las potenciales cepas productoras de $\beta$-lactamasa de expectro extendido $(\beta L E E)$ se analizaron en doble difusión por disco, de acuerdo a las recomendaciones internacionales ${ }^{10}$. El análisis se efectuó con aquellos pacientes cuyo urocultivo confirmó el diagnóstico de ITU.

Se efectuó análisis estadístico descriptivo con medidas de concentración y frecuencias en el programa Epi Info versión 3.4.1.

\section{Resultados}

En el período asignado, 238 niños con sospecha de ITU febril, consultaron en la UEI del CADSR y fueron derivados para TAIA a la UHT siendo la mala tolerancia oral la indicación de tratamiento intravenoso en todos ellos. Fueron excluidos 118 niños por no cumplir los criterios de inclusión, 120 fueron enrolados, se eliminaron nueve de ellos por urocultivo de ingreso negativo o contaminado y seis no se incluyeron en el análisis por tener datos incompletos. El análisis de los resultados se hizo con los 105 restantes (Figura 1).

\section{Características demográficas}

Distribución por sexo: 80/105 pacientes eran mujeres (76,2\%), la relación mujer-hombre fue 4:1 en el grupo de 2-12 meses, aumentando a 6:1 entre los 1 y 5 años. La mediana de edad fue 14 meses (rango 3-51) y más del 80\% de los pacientes tenía 18 meses o menos, concentrándose la mitad de ellos en el rango de 6 a 12 meses (Figura 2).

\section{Hallazgos en el examen microscópico de orina}

En 87/105 pacientes (82,9\%) el examen microscópico de orina fue indicador de ITU y en todos ellos se detectó bacteriuria; 14 de los 18 pacientes $(77,8 \%)$ que tuvieron menos de 5 leucocitos en orina presentaron también bacteriuria.

\section{Hallazgos en el urocultivo}

En 100/105 niños $(96,1 \%)$ se aisló E. coli en el urocultivo, en tres se encontró $P$. mirabilis $(1,9 \%)$, en uno creció $K$. oxytoca (1\%) y en otro K. pneumoniae (1\%).

\section{Susceptibilidad in vitro}

Las cepas de E. coli aisladas tuvieron buena sensibilidad a los aminoglucósidos testeados (amikacina y gentamicina; 100 y 97\%, respectivamente), así como a quinolonas (97\%) y cefalosporinas de tercera generación (cefotaxima y ceftazidima, 99\% para ambas). La sensibilidad para cefalosporina de primera generación (cefalotina, 69\%), cotrimoxazol (66\%) y ampicilina/ sulbactam (58\%) fue deficiente. La totalidad de las cepas 
fue sensible a nitrofurantoína. Un $12 \%$ de las cepas de $E$. coli tuvo sensibilidad intermedia a cefalotina. Las cepas de $P$. mirabilis fueron sensibles a todos los antimicrobianos estudiados, excepto a nitrofurantoína, explicado por la resistencia intrínseca de este microorganismo a este antimicrobiano (Tabla 1). La cepa de $K$. pneumoniae fue sensible a todos los antimicrobianos y $K$. oxytoca fue resistente a ampicilina/sulbactam y cotrimoxazol.

Figura 1. Niños con sospecha de ITU consultantes en Emergencia Infantil del CADSR. Noviembre de 2009-noviembre de 2010.

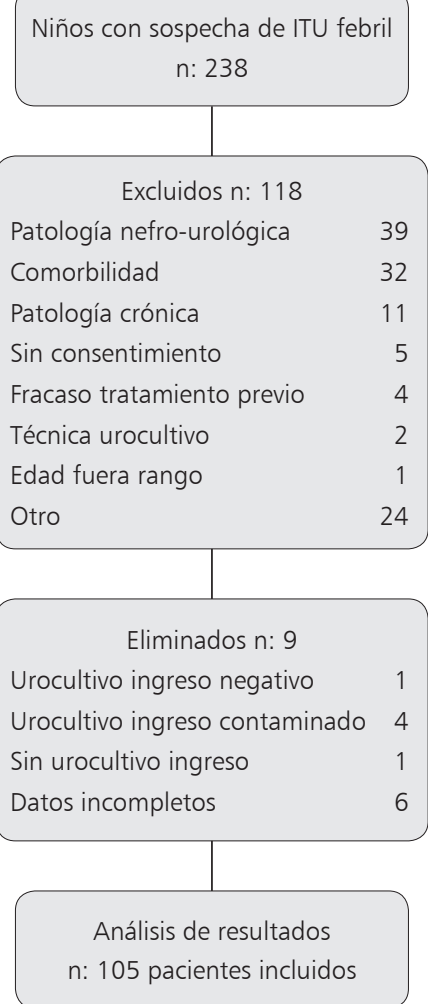

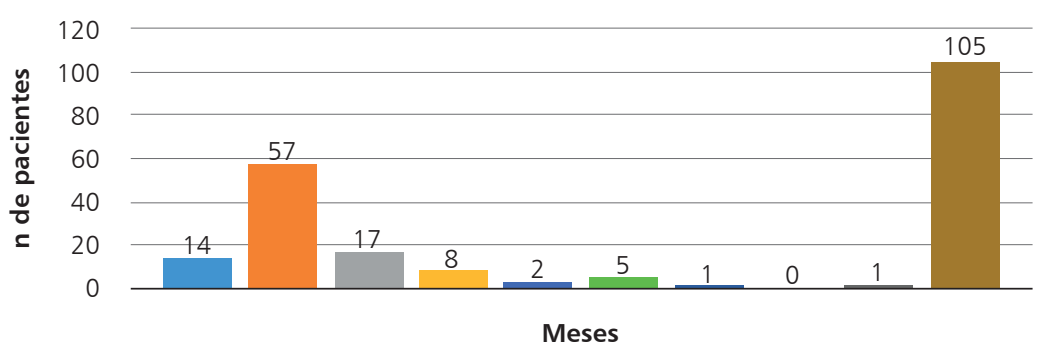

Rango de edades en meses

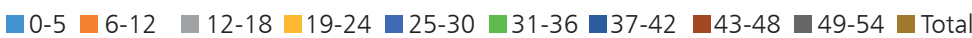

Figura 2. Distribución de los pacientes con primer episodio de ITU febril según rango de edad, CADSR. Noviembre de 2009-noviembre de 2010.
Tabla 1. Susceptibilidad in vitro, expresada en porcentaje de cepas sensibles, de los uropatógenos aislados en niños con ITU, CADSR. Noviembre de 2009-noviembre de 2010

\begin{tabular}{lcc|} 
Antimicrobiano & E. coli & P. mirabilis \\
n: 100 & n: 3 \\
Ampicilina/sulbactam & 58 & 100 \\
Cefalotina & 69 & 100 \\
Ceftazidima & 99 & 100 \\
Cefotaxima & 99 & 100 \\
Amikacina & 100 & 100 \\
Gentamicina & 97 & 100 \\
Ciprofloxacina & 97 & 100 \\
Cotrimoxazol & 66 & 100 \\
Nitrofurantoína & 100 & 0 \\
\hline
\end{tabular}

A 13 pacientes $(12,4 \%)$ se les tomó hemocultivo y en ninguno hubo crecimiento bacteriano.

\section{Tratamiento antimicrobiano}

El 83,8\% de los pacientes se trató con amikacina, 8,6\% con ceftriaxona y $7,6 \%$ con ambos. El promedio de días de tratamiento intravenoso fue 3,1 $\pm 1,1$ días. El antimicrobiano más utilizado vía oral fue cefadroxilo $(69,5 \%)$ seguido de cefpodoxima (30,5\%). El tratamiento vía oral duró en promedio $4,3 \pm 1,2$ días.

En una lactante de nueve meses, sin antecedentes de hospitalización ni uso previo de antimicrobianos, se encontró una cepa de $E$. coli productora de $\beta$ LEE, la que presentó resistencia a ampicilina/sulbactam, cefalotina, cefotaxima, ceftazidima, ciprofloxacina, cotrimoxazol y fue sensible a amikacina, gentamicina, nitrofurantoína, imipenem, ertapenem y cefoperazona/sulbactam. Fue tratada con amikacina intravenosa durante seis días y el urocultivo tomado cinco días después de terminado el tratamiento fue negativo.

El urocultivo de control se hizo en 100/105 (95,2\%), resultando negativo en $97(97 \%)$ y contaminado en tres (todos se repitieron y fueron negativos).

Ningún paciente se hospitalizó por la ITU y todos evolucionaron sin complicaciones y fueron derivados al Departamento de Nefrología Infantil para su seguimiento.

\section{Discusión}

En este estudio comunicamos la etiología y susceptibilidad antimicrobiana del primer episodio de ITU febril en una cohorte de niños atendidos en el área suroriente de la Región Metropolitana. Los hallazgos demográficos son concordantes con lo descrito en la literatura médica, 
destacando la mayor prevalencia en el sexo femenino en todas las edades ${ }^{1,11} \mathrm{y}$ un predominio de lactantes menores (6 a 12 meses $)^{11}$.

En niños pequeños con ITU, la fiebre es de especial importancia como marcador clínico de compromiso del parénquima renal (pielonefritis) ${ }^{4,12}$. Un diagnóstico oportuno y un tratamiento antimicrobiano precoz son fundamentales para prevenir las secuelas a largo plazo. Por ello, es importante minimizar los falsos negativos como los falsos positivos, para evitar tratamientos antimicrobianos y exámenes de laboratorio innecesarios que determinen molestias para el paciente y mayor costo económico. Nos parece importante destacar que cuando debe tomarse una decisión terapéutica es recomendable utilizar aquellos métodos de recolección con menor probabilidad de contaminación, por lo que el cateterismo trans-uretral debería emplearse siempre en los niños sin control voluntario del esfínter urinario ${ }^{13}$. En la literatura médica se han publicado muy variadas tasas de contaminación en relación a los métodos de obtención de las muestras de orina, especialmente para aquellas obtenidas por segundo chorro, oscilando entre 0 y $85 \%$. Esto se debe probablemente a diferentes técnicas de recolección y definiciones, lo cual dificulta la comparación entre estudios. En un trabajo reportado recientemente, las muestras obtenidas por segundo chorro presentan una tasa de contaminación de hasta $26 \%$, las por cateterismo vesical de $12 \%$ y aquellas por punción suprapúbica sólo de $1 \%{ }^{14}$. La necesidad de técnicas más precisas resulta de mayor importancia en aquellos escenarios en que el niño no puede ser controlado con la frecuencia deseada, como suele ocurrir en la población de este estudio. Existen pocos trabajos que evalúen las complicaciones del cateterismo vesical generadas en niños sometidos a este procedimiento transitoriamente. Un reporte español encontró 4,5\% de complicaciones en 116 pacientes (dolor referido al área genital, hematuria no confirmada e ITU 12 días después del cateterismo $)^{15}$. Consideramos que, si bien el cateterismo vesical es una técnica efectiva y segura, es invasora y requiere una supervisión constante para asegurar una adecuada realización del procedimiento.

Nuestra serie correspondió a una cohorte de pacientes tratados con TAIA, cuya indicación en 100\% fue la mala tolerancia oral, lo que puede constituir un sesgo de selección ya que no podemos asegurar que los pacientes tratados con antimicrobianos orales tengan un perfil etiológico y de susceptibilidad antimicrobiana diferente. Tampoco se incluyó a los pacientes con morbilidad nefro-urológica conocida, con la finalidad de que correspondiera efectivamente al primer episodio y minimizar la posibilidad de resistencia antimicrobiana.

Es interesante mencionar que en este estudio un grupo de pacientes presentó examen de orina sin leucocituria (18 niños), en su mayoría asociada a bacteriuria y con urocultivo positivo. Existe la discusión actualmente de si estos casos corresponderían a verdaderas infecciones urinarias o a cuadros de bacteriuria asintomática ${ }^{16}$. Sabemos que la leucocituria puede faltar en las fases iniciales de la infección urinaria, principalmente si la consulta es precoz y, si bien existen guías clínicas que sugieren no tratar los episodios de bacteriuria asintomática ${ }^{4,17}$; nos parece razonable indicar antibioterapia a los pacientes con examen de orina normal pero con urocultivo positivo, particularmente si presentan síntomas como fiebre.

En concordancia con lo reportado en la literatura médica, E. coli fue el patógeno más frecuente en esta cohorte de pacientes, seguido por otros microorganismos gramnegativos de la familia Enterobacteriaceae (Proteus spp y Klebsiella spp $)^{11,18,19}$. Encontramos una elevada resistencia de E. coli a cefalosporinas de primera generación, cotrimoxazol y ampicilina/sulbactam, en concordancia con lo descrito en otras series extranjeras ${ }^{20}$ y nacionales ${ }^{21-23}$. El porcentaje de cepas sensibles a cefalotina encontrado en nuestra serie es inferior al detectado por Camponovo ${ }^{22}$ en niños de la Región Metropolitana en el período 2007-2008 (69 vs $85 \%$ ) y similar a la reportada por Silva ${ }^{23}$ en niños ambulatorios de las regiones de Tarapacá (I), Valparaíso (V), Bío-Bío (VIII) y Región Metropolitana (67,9\%). La resistencia creciente a cefalosporinas de primera generación podría estar asociada al amplio uso de estos fármacos en la práctica clínica ${ }^{24}$, ya que son los antimicrobianos de elección para el tratamiento empírico de las ITUs y otras infecciones adquiridas en la comunidad y existe evidencia que sugiere una relación entre la prescripción y la resistencia antimicrobiana ${ }^{24,25}$. La sensibilidad intermedia a cefalotina, que alcanzó a $12 \%$ en este grupo, fue inferior a la encontrada por Ewertz ${ }^{26}$ en niños entre 0 y 15 años ambulatorios y hospitalizados (19\% del $\mathrm{H}$. Militar y $42 \%$ en el H. Parroquial de San Bernardo, ambos de Santiago). Si bien se puede anticipar eficacia clínica en el tratamiento de cepas con sensibilidad intermedia a cefalosporinas de primera generación, considerando que este antimicrobiano alcanza buena concentración en orina, no es posible asegurar éxito terapéutico toda vez que hay múltiples factores tanto del hospedero como del microorganismo que influencian la respuesta clínica. En nuestro grupo de pacientes se mantuvo una buena sensibilidad in vitro de E. coli a aminoglucósidos, la que se ha observado en más de una década a pesar del uso frecuente de estos fármacos en la práctica clínica. Lo mismo se observó para cefalosporinas de tercera generación.

Destacamos el hallazgo de una cepa de E. coli productora de $\beta$ LEE en una niña sin los factores de riesgo descritos para adquirir este tipo de microorganismos. En la literatura médica se ha reportado la presencia creciente de Enterobacteriaceas con mecanismos de resistencia a los $\beta$ lactámicos ITUs adquiridas en la comunidad ${ }^{27,28}$. Estos estudios insisten en el uso racional de antimicrobianos y 
cuestionan el uso de profilaxis antimicrobiana después de un episodio de ITU en niños ante el riesgo potencial de generar resistencia. Es necesario que se evalúe periódicamente la resistencia antimicrobiana considerando que probablemente se observen variaciones debido a la restricción de indicación de profilaxis contenida en las recomendaciones actuales sobre manejo de ITU ${ }^{9}$.

Consideramos que la elección empírica del tratamiento antimicrobiano debe basarse en el conocimiento de la prevalencia local de microorganismos y su susceptibilidad in vitro, dado que los patrones de resistencia pueden variar en diferentes regiones. Existen variaciones geográficas considerables en los patrones bacterianos de resistencia, dependiendo de las prácticas locales de prescripción de antimicrobianos $^{18,24}$.

Si bien encontramos una buena sensibilidad a nitrofurantoína, consideramos que es una alternativa de tratamiento para ITU afebril no complicada y para uso profiláctico en los casos en que esté indicado ${ }^{29,30}$. Nitrofurantoína alcanza elevadas concentraciones en la orina después de su administración oral, pero no así concentraciones bactericidas en sangre y en el parénquima renal $^{29}$ por lo que no se recomienda su uso en infecciones bacterianas sistémicas, donde se requiere elevadas concentraciones séricas y tisulares del antimicrobiano. Por lo tanto, a pesar de su buena actividad in vitro, no es recomendable en niños con ITU febril, especialmente en aquellos más pequeños, con mayor riesgo de cicatriz renal.

De acuerdo a nuestros hallazgos de susceptibilidad in vitro, recomendamos que en niños de este grupo etario con ITU febril del área suroriente de Santiago se inicie tratamiento antimicrobiano empírico con aminoglucósidos o cefalosporinas de tercera generación cuando la vía intravenosa sea la indicada y hasta obtener el resultado del antibiograma. No es posible efectuar una recomendación fundamentada para aquellos con indicación de tratamiento vía oral ya que el laboratorio de microbiología no efectúa testeo de rutina para cefalosporinas de segunda o tercera generación de uso oral, considerando que probablemente las cepas de E.coli sean porcentualmente más susceptibles a dichas cefalosporinas que a las de primera generación.

No existen publicaciones nacionales actualizadas acerca del patrón de resistencia antimicrobiana de los patógenos que causan el primer episodio de ITU febril en niños con características similares a la serie presentada por lo que creemos que este estudio representa un aporte en la decisión terapéutica.

\section{Resumen}

Introducción: La infección del tracto urinario (ITU) es muy frecuente en la niñez y su diagnóstico implica la realización de urocultivo. Objetivo: Describir la etiología y susceptibilidad bacteriana del primer episodio de ITU en niños que consultaron por fiebre en una unidad de emergencia. Pacientes y Métodos: Se evaluaron 105 niños ( 2 meses-5 años) consultantes en la Unidad de Emergencia Infantil del Hospital Sótero del Río del área sur-oriente de Santiago entre noviembre de 2009 y noviembre de 2010 , con muestra de orina tomada por cateterismo trans-uretral para sedimento de orina, urocultivo y antibiograma. $R e$ sultados: El 76,2\% (80) de los pacientes fueron mujeres y $80 \%$ (84) tenía menos de 18 meses. El sedimento de orina resultó alterado en $82,5 \%$. El microorganismo aislado con mayor frecuencia fue Escherichia coli (96,1\%) que mostró buena susceptibilidad in vitro (cercana a 100\%) para aminoglucósidos, cefalosporinas de tercera generación, quinolonas y nitrofurantoína, y baja susceptibilidad para cefalotina $(69 \%)$ y cotrimoxazol $(66 \%)$. Una cepa era productora de $\beta$-lactamasa de expectro extendido ( $\beta$ LEE). Conclusión: El uropatógeno más frecuente fue $E$. coli que demostró buena susceptibilidad in vitro a aminoglucósidos y cefalosporinas de tercera generación, antimicrobianos parenterales recomendados como tratamiento empírico inicial para este grupo de pacientes. Las cepas de E. coli productoras de $\beta$ LEE aparecen como patógenos emergentes en las ITUs adquiridas por niños en la comunidad.

\section{Referencias bibliográficas}

1.- Cavagnaro F. Infección urinaria en la infancia. Rev Chilena Infectol 2005; 22 (2): 161-8

2.- Salas P, Álvarez E, Saieh C. Pautas de diagnóstico y tratamiento en infección urinaria en niños. Documento de la Rama de Nefrología de la Sociedad Chilena de Pediatría. Rev Chil Pediatr 2003; 74 (3): 311-4.

3.- Urinary Tract Infection: Clinical practice guideline for the diagnosis and management of the initial UTI in febrile infants and children 2 to 24 months, Subcommittee on Urinary Tract Infection and Steering Committee on Quality
Improvement and Management. Pediatrics 2011; 128 (3): 595-610.

4.- American Academy of Pediatrics, Committee on Quality Improvement. Subcommittee on Urinary Tract Infection. Practice parameter: the diagnosis, treatment and evaluation of the initial urinary tract infection in febrile infants and young children. Pediatrics 1999; 103: 843-52.

5.- Urinary tract infection in children. Diagnosis, treatment and long term management. National Collaboring Centre for Woman's and Children's Health. Clinical Guideline. August 2007.

6.- Lizama M, Luco M, Reichhard C, Hirsh T. Infección del tracto urinario en un servicio de urgencia pediátrico: frecuencia y características clínicas. Rev Chilena Infectol 2005; 22: 235-4.

7.- Yoon J E, Kim W K, Lee J S, Shin K, Ha T. Antibiotic susceptibility and imaging findings of the causative microorganisms responsible for acute urinary tract infection in children: a fiveyear single center study. Korean J Pediatr 2011; 54 (2): 79-85.

8.- Peña A, Viviani T, Le Corre N, Morales V, Montecinos C, Gajardo C. Manejo de la infección del tracto urinario en lactantes febriles: Experiencia de tratamiento antimicrobiano intravenoso ambulatorio. Rev Chilena Infectol 2009; 26 (4): 350-4. 
9.- Salas P, Barrera P, González C, Zambrano P, Salgado I, Quiroz L, et al. Actualización en el diagnóstico y manejo de la infección urinaria en pediatría. Rev Chil Pediatr 2012; 83 (3): 269-78.

10.- National Committee for Clinical Laboratory Standards (NCCLS). Methods for dilution antimicrobial susceptibility tests for bacteria that grow aerobically. Approved standard

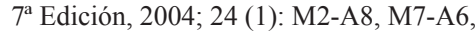
pág 25-6.

11.- Ceballos O, Erazo I, López R, Fuentes R, Campillay C. Caracterización de lactantes con infección del tracto urinario. 2009-2010. Hospital Regional de Antofagasta. Revista ANACEM 2010; 4: 14-7.

12.- Saadeh $S$, Mattoo T. Managing urinary tract infections. Pediatr Nephrol 2011; 26 1967-76.

13.- Cavagnaro F. Infección urinaria en pediatría: controversias. Rev Chilena Infectol 2012; 29 (4): 427-33.

14.- Tosif S, Baker A, Oakley E, Donath S, Babl FE. Contamination rates of different urine collection methods for the diagnosis of urinary tract infections in young children. J Pediatr Child Health 2012; 48: 659-64.

15.- Gómez Vásquez S H, Oñoro G, de la Torre Espí M, Martin Díaz M J, Novoa-Carballal R, Molina Cabañero J C. Complications of bladder catheterization to obtain a urine simple in the emergency department. An Pediatr (Barc) 2011; 75 (4): 253-8.

16.- Bachur R, Harper M B. Reliability of the urinalysis for predicting urinary tract infections in young febrile children. Arch Pediatr Adolesc Med 2001; 155 (1): 60-5.

17.- National Collaborating Centre for Women's and
Children's Health: National Institute for Health and Clinical Excellence. NICE Guideline CG54 Urinary tract infection: diagnosis, treatment and long-term management of urinary tract infection in children. August 2007. http://www.nice. org.uk/nicemedia/live/11819/36030/36030.pdf (accedido el 6 de junio de 2013).

18.- Chakupurakal R, Ahmed M, Sovbithadevi D N, Chinnappan S, Reynolds T. Urinary tract pathogens and resistance pattern. J Clin Pathol 2010; 63: 652-4.

19.- Akram M, Shahid M, Khan AU. Etiology and antibiotic resistance patterns of communityacquired urinary tract infections in J N M C Hospital Aligarh, India. Ann Clin Microbiol Antimicrob 2007; 6: 4.

20.- Caracciolo A, Bettinelli A, Bonato C, Isimbaldi C, Tagliabue A, Longoni L, et al. Antimicrobial resistance among Escherichia coli that cause childhood community-acquired urinary tract infections in Northern Italy. Italian J Pediatr 2011; 37: 3 http://www.ijponline. net/content/37/1/3 (accedido el 5 de enero de 2013).

21.- Prado V, Trucco O, Durán C, Mamani R, Royer M y Grupo PRONARES. Perfil de resistencia a los antimicrobianos en agentes causantes de infección del tracto urinario en niños chilenos. Programa de vigilancia PRONARES. Rev Med Chile 2001; 129 (8): $877-85$.

22.- Camponovo R. Susceptibilidad bacteriana a antimicrobianos. Especies aisladas en pacientes ambulatorios de la Región Metropolitana, Chile, año 2007. Rev Chilena Infectol 2009; 26 (1): $18-20$.

23.- Silva F, Cifuentes M, Pinto M E. Resultados de la vigilancia de susceptibilidad antimicrobiana en Chile: Consolidando una red. Rev Chilena Infectol 2011; 28 (1): 19-27.

24.- Catal F, Bavbek N, Bayrac O, Karabel M, Karabel D, Odemis E, et al. Antimicrobial resistance patterns of urinary tract pathogens and rationale for empirical therapy in Turkish children for the years 2000-2006. Int Urol Nephrol 2009; 41: 953-7.

25.- Brozwaer S L, Cars O and participants in the European Antimicrobian Surveillance System, et al. A European study on the relationship between antimicrobial use and antimicrobial resistance. Emerg Infect Dis J 2002; 21: 957-9.

26.- Ewertz E, Endeiza M L, González F, Figueroa D, Rojas P, Porte L, et al. Estudio colaborativo sobre la epidemiología y susceptibilidad antimicrobiana de las infecciones del tracto urinario (ITU) en pacientes pediátricos de Santiago. Rev Chil Pediatr 2012; 83 (Supl N 1): s 82.

27.- Bitsori M, Maraki S, Kalmanti M. Resistance against broad spectrum $\beta$ lactams among uropathogens in children. Pediatr Nephrol 2009; 24: 2381-6.

28.- Ramos N L, Dzung D T, Stopsack K, Jankó V, Pourshafie M, Katouli M, et al. Characterization of uropathogenic Escherichia coli from children with urinary tract infection in different countries. Eur J Clin Microbiol Infect Dis 2011; 30: $1587-93$

29.- Bagga A, Mantan Mukta. Oral antibiotics for febrile urinary tract infections. Pediatr Nephrol 2003; 18: 479-80.

30.- Beetza R, Westenfelderb M. Antimicrobial therapy of urinary tract infections in children. Int J Antimicrob Agents 2011; 38 (Suppl): 42-50. 